OPUSCULA MUSEALIA 262019

doi:10.4467/20843852.OM.18.005.10998

s. $51-57$

EWA WYKA 이 https://orcid.org/0000-0003-3822-7377

Instytut Historii Nauki im. Ludwika i Aleksandra Birkenmajerów PAN

Muzeum Uniwersytetu Jagiellońskiego

\title{
Krakowskie pamiątki po Jędrzeju Śniadeckim
}

\author{
ABSTRACT \\ Jędrzej Śniadecki memorabilia from Kraków
}

This article presents the results of a search for memorabilia related to Jędrzej Śniadecki (1768-1838), a prominent Polish chemist, doctor and columnist. He was born in Żnin in Greater Poland, educated in Kraków and his professional life was associated with Vilnius. This search for memorabilia related to Jędrzej Śniadecki (except for archival materials) was conducted in Vilnius and Kalczuny in Belarus, which has a school museum devoted to Jędrzej Śniadecki and other scholars. However, no personal belongings related to the scholar were found at these locations. At present, the only items known to have belonged to Jędrzej Śniadecki are included in the collection of the Jagiellonian University in Kraków. These items are: an $18^{\text {th }}$-century microscope, a line gauge dating to 1834 and a ceremonial spade which formed an element of the academic regalia worn by professors of the Imperial University of Vilnius. The article discusses the above mentioned items and their provenance. In 1964, the microscope was transferred to the Jagiellonian University Museum in Kraków from the Botany Unit of the Jagiellonian University by Professor Władysław Szafer (18861970) with the information that it had belonged to Jędrzej Śniadecki.

It is a Cuff-type microscope made of wood, cardboard, bone and glass, manufactured in Nuremberg. The microscope attributed to Śniadecki bears the initials JFF. It is not a high quality product, but microscopes from Nuremberg gained popularity as toys rather than test instruments.

The second item attributed to Jędrzej Śniadecki is a 24-inch folding line gauge which consists of two parts. It was bought in 1957 by the Jagiellonian University Museum from Professor Andrzej Ciechanowiecki, who had inherited it in 1945 from Maria Kazimierzowa Osiecimska-Czapska (née Śniadecka), a great-granddaughter of Jędrzej Śniadecki. In the family, this item was regarded as a memento of Jędrzej Śniadecki which came from Boltup. 
Another memento of the scholar is a ceremonial spade. Tradition has it that it belonged to Jędrzej Śniadecki and was an element of the ceremonial regalia worn by the professors of the Imperial University of Vilnius. In 1878, the spade was donated to the Archaeological Cabinet of the Jagiellonian University by Kazimierz Jan Wilczyński (1806-1885), a doctor, art collector, publisher and member of the Vilnius Temporary Archaeological Commission.

Keywords: Jędrzej Śniadecki, objects related to Jędrzej Śniadecki, Jagiellonian University Museum, Bołtupie

Słowa kluczowe: Jędrzej Śniadecki, pamiątki po Jędrzeju Śniadeckim, Muzeum Uniwersytetu Jagiellońskiego, Bołtupie

Jędrzejowi Śniadeckiemu, jego życiu, osiągnięciom zawodowym i działalności społecznej badacze poświęcili bardzo wiele uwagi. Źródłem wiedzy o uczonym są liczne opracowania, począwszy od jednych z najwcześniejszych prac Michała Balińskiego z 1840 roku, przez monografię w języku polskim Lucjana Chrzęściewskiego z 1978 roku Jędrzej Śniadecki: życie $i$ dzieło z bogatą literaturą źródłową do najnowszej, obszernej monografii w języku litewskim zatytułowanej Andrius Sniadeckis autorstwa Birute Railienė z 2005 roku$^{1}$. Autorka w swej pracy publikuje pełną bibliografię prac Jędrzeja Śniadeckiego oraz opracowań i artykułów dotyczących jego osoby. Jej zestawienie, obejmujące lata 1801-2004, liczy 687 pozycji, z czego 561 to prace poświęcone uczonemu.

Pojawia się pytanie, czy oprócz materiałów archiwalnych przetrwały do dziś jakieś przedmioty osobistego użytku należące do uczonego. Można byłoby przypuszczać, że długoletnia aktywność zawodowa Śniadeckiego jako lekarza, przyrodnika upoważnia do oczekiwań znacznej spuścizny po uczonym, w szczególności w Wilnie, gdzie spędził on większość swego 70-letniego życia.

Prowadzona tam kwerenda w kierunku materialnych pamiątek po Jędrzeju nie przyniosła spodziewanych rezultatów. W zbiorach Muzeum Uniwersytetu Wileńskiego nie ma przedmiotów związanych z Jędrzejem Śniadeckim. Podobnie Litewskie Muzeum Narodowe w Wilnie nie posiada pamiątek po uczonym. Również w miejscowości Bołtupie, majątku Śniadeckiego niedaleko Wilna, nie zachowały się pamiątki po Jędrzeju lub jego rodzinie.

Wydaje się, że jedyne przedmioty należące do Jędrzeja Śniadeckiego lub przypisywane mu znajdują się w zbiorach Uniwersytetu Jagiellońskiego w Krakowie. W Muzeum Uniwersytetu Jagiellońskiego przechowywane są trzy obiekty muzealne przypisywane uczonemu. Nie są one związane z jego okresem studiów w Krakowie. Pozyskane zostały przez Uniwersytet później, w XIX i XX wieku. Są to dwa przyrządy: mikroskop optyczny i przymiar liniowy oraz szpada paradna do stroju profesorskiego Cesarskiego Uniwersytetu Wileńskiego.

Mikroskop przekazany został do muzeum w 1964 roku z Zakładu Botaniki UJ przez profesora Władysława Szafera (1886-1970) z informacją, że przyrząd należał do Jędrzeja

${ }^{1}$ M. Baliński, Dzieła Jędrzeja Śniadeckiego, t. 1, Warszawa 1840; idem, Życie Jędrzeja Śniadeckiego, Leszno, Gniezno 1840; L. Chrzęściewski, Jędrzej Śniadecki: życie i dzieło, Kraków 1978; B. Railienè, Andrius Sniadeckis, Vilnius 2005. 
Śniadeckiego (il. IV). Jest to mikroskop typu Cuffa, wykonany z drewna, tektury, kości i szkła ${ }^{2}$. Zasadnicze elementy przyrządu - tubus z okularem i obiektywem oraz stolik przedmiotowy Bonanniego ${ }^{3}$ (sprężyna dociskająca preparat) - osadzone są wspólnie na jednym filarze, mocowanym do podstawy. Stanowi ją drewniana skrzynka, w której przechowywane są płytki z preparatami i wymienne obiektywy. W podstawie osadzone jest płaskie lusterko uchylne oświetlające płytkę z preparatami. Ostrość obrazu uzyskiwano, regulując wzajemne położenia tubusa z obiektywem, części tubusa z okularem i stolika przedmiotowego. Tego typu mikroskopy, zwane również norymberskimi, produkowane były w XVIII wieku w Norymberdze przez wytwórców zabawek. Niektóre z nich były sygnowane. Mikroskop przypisywany Śniadeckiemu sygnowany jest inicjałami JFF4. Przyrządy z identyczną sygnaturą, różnej konstrukcji, znajdują się do dziś w muzeach i prywatnych zbiorach ${ }^{5}$. Mikroskopy norymberskie nie są traktowane jako przyrządy badawcze, jednakże omawiany przyrząd dzięki wymiennym obiektywom umożliwiał stosunkowo dokładną obserwację preparatu.

Kolejny przedmiot należący według tradycji do Jędrzeja Śniadeckiego to dwuczęściowy przymiar składany, 24-calowy, datowany na rok 1834 (il. II). Zakupiony został do zbiorów Muzeum UJ w 1957 roku od profesora Andrzeja Ciechanowieckiego, który odziedziczył go po mieszkającej w Krakowie od 1919 roku i zmarłej w 1945 roku prawnuczce Jędrzeja Śniadeckiego - Marii ze Śniadeckich Kazimierzowej Osiecimskiej-Czapskiej ${ }^{6}$. W rodzinie przyrząd uchodził jako pochodząca z Bołtupia pamiątka po Jędrzeju Śniadeckim.

To przymiar składany, jego ramię mosiężne chowane jest w szczelinie ramienia drewnianego. Na mosiężnym ramieniu wyryto datę 1834 oraz obustronnie podziałkę, wyrażoną w calach pruskich (24 cali; każdy z cali dzielony na 4 części - 3 linie) ${ }^{7}$. Na drewnianym ramieniu przymiaru skala znaczona jest metalowymi punktami i tłoczonymi cyframi. Nie wiadomo, w jaki sposób Jędrzej Śniadecki wszedł w posiadanie przymiaru skalowanego w calach pruskich. Uczony przybył do Wilna w 1797 roku i całe dalsze życie związał z tym miastem, znajdującym się w zaborze rosyjskim. W 1834 roku Jędrzej Śniadecki przebywał w Wilnie, gdzie od 1827 roku pełnił funkcję kierownika Kliniki Uniwersytetu Wileńskiego ${ }^{8}$. Na terenie Imperium Rosyjskiego w tym okresie stosowano różne miary.

2 John Cuff (ok. 1708-ok. 1772) - londyński mechanik czynny w latach 1731-1770, skonstruował m.in. mikroskopy, w których poszczególne elementy osadzone były na jednym filarze; znany z konstrukcji mikroskopu „,wodnego”, który służył do obserwacji obiektów w warstwie cieczy, $c f$. G. Clifton, Directory of British Scientific Instrument Makers 1550-1851, London 1995, s. 73.

${ }^{3}$ Filipo Bonanni (1638-1725) - włoski przyrodoznawca, zoolog, entomolog o licznych innych zainteresowaniach. W swych badaniach wykorzystywał również mikroskop.

${ }^{4}$ M. Taborska, Mikroskop optyczny po prof. Jędrzeju Śniadeckim, karta katalogu naukowego Muzeum Uniwersytetu Jagiellońskiego nr MUJ 4136, 136/V.

${ }^{5}$ Mikroskopy tego typu zachowały się w zbiorach muzealnych m.in. w Science Museum w Londynie A129196 A97436, A95413, lub the Golub Collection w the University of California, Berkeley, obiekt nr 60, http://golubcollection.berkeley.edu/18th/60.html [dostęp: 3.01.2019].

${ }^{6}$ Maria Antonina Osiecimska-Hutten Czapska (1876-1945) - córka Andrzeja Śniadeckiego, wnuka Józefa Śniadeckiego, syna Jędrzeja, żona Kazimierza Roberta Osiecimskiego-Hutten Czapskiego.

71 cal pruski w latach $1817-1872$ równy był 0, $0261545 \mathrm{~m}=12$ linii. Vide D. Fenna, Jednostki miar. Leksykon, red. B. Pierzchalska, przeł. J. Gronkowski, J. Kuśmierczyk, Warszawa 2004, s. 37.

${ }^{8}$ L. Chrzęściewski, op. cit., s. 23. 
Ujednolicenie na podstawie wzorców angielskich wprowadził Mikołaj I ustawą z 1835 roku, a od ukazu z 1842 zaczęły obowiązywać miary rosyjskie9.

Trzecim obiektem muzealnym związanym z uczonym jest szpada paradna, według tradycji należąca do Jędrzeja Śniadeckiego (il. III). Stanowiła ona element stroju paradnego profesora Cesarskiego Uniwersytetu Wileńskiego. Uniwersytet pod tą nazwą funkcjonował w latach 1803-1832, powołany w miejsce Szkoły Głównej Wileńskiej. Od 5 maja 1806 roku wprowadzono togi i mundury profesorskie i ustanowiono godła wydziałowe ${ }^{10}$. Szpada podarowana została w 1878 roku do Gabinetu Archeologicznego UJ przez Kazimierza Jana Wilczyńskiego (1806-1885) - lekarza, kolekcjonera dzieł sztuki, wydawcę, członka Tymczasowej Komisji Archeologicznej Wileńskiej ${ }^{11}$. Gabinet Archeologiczny UJ zorganizowany i prowadzony był przez profesora Józefa Łepkowskiego, który podobnie jak Kazimierz Wilczyński był członkiem Komisji Archeologicznej Wileńskiej. W notatkach zamieszczonych w katalogu Gabinetu znajduje się informacja, że szpada wypożyczona została przez Jana Matejkę jako rekwizyt przy pracy nad obrazem Kościuszko pod Racławicami (1888) ${ }^{12}$.

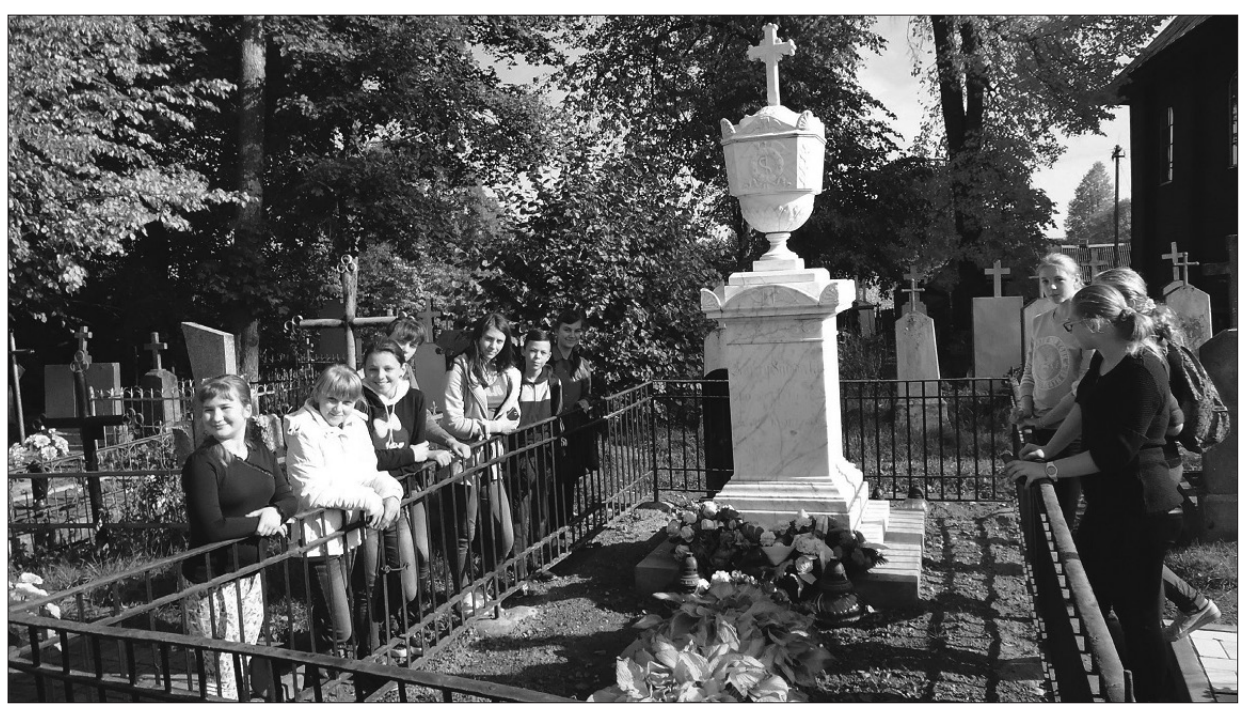

Il. 1. Pomnik nagrobny Jędrzeja Śniadeckiego w Horodnikach [w:] T. Dawidowicz, Pamięć o Jędrzeju Śniadeckim na Oszmiańszczyźnie, „Pałuki” 2018, nr 1, s. 13

9 A. Barański, L.Z. Warsza, Miary na ziemiach polskich $w$ dobie porozbiorowej, „Pomiary, Automatyka, Kontrola PAK” 2012, vol. 58, nr 12, s. 1138.

10 J. Bieliński, Życie Jędrzeja Śniadeckiego, s. 477.

${ }^{11}$ Komisja założona została w 1855 r. przez Eustachego Tyszkiewicza, twórcę Muzeum Starożytności, ulokowanego w budynkach zlikwidowanego Uniwersytetu Wileńskiego. Komisja zajmowała się ewidencjonowaniem i badaniem źródeł do dziejów Wielkiego Księstwa Litewskiego. Była to placówka naukowa, w latach 1856-1858 wydawała „Pamiętnik Komisji Archeologicznej”.

${ }^{12}$ Katalog kartkowy Gabinetu Archeologicznego UJ, Muzeum UJ; M. Gajek, Szpada wg tradycji po Jędrzeju Śniadeckim, karta katalogu naukowego Muzeum UJ. 
Dotychczas nie znaleziono więcej osobistych pamiątek po uczonym, nie licząc materiałów archiwalnych. Warto natomiast wspomnieć o działaniach na rzecz zachowania pamięci po uczonym. Miejscem pochówku Jędrzeja Śniadeckiego są Horodniki, dziś w granicach Białorusi. Cmentarzem w Horodnikach opiekuje się społeczność Szkoły Średniej w Kolczunach na Oszmiańszczyźnie - miejscowości położonej niedaleko majątku Śniadeckiego Bołtupie. Z inicjatywy lokalnej społeczności w 2012 roku pomnik nagrobny Jędrzeja Śniadeckiego został odnowiony (il. 1). Prowadzone prace wsparte zostały finansowo przez Ministerstwo Kultury i Dziedzictwa Narodowego. Obecnie o pomnik dba młodzież szkoły w Kolczunach.

Zastępca dyrektora szkoły Pani Tatiana Dawidowicz zorganizowała również na jej terenie muzeum historyczno-krajoznawcze Uczeni naszej ziemi. Liczny zbiór prezentowanych na wystawie materiałów dotyczy Jędrzeja Śniadeckiego. Są to reprodukcje archiwaliów, fotografii i dzieła uczonego (il. 2).

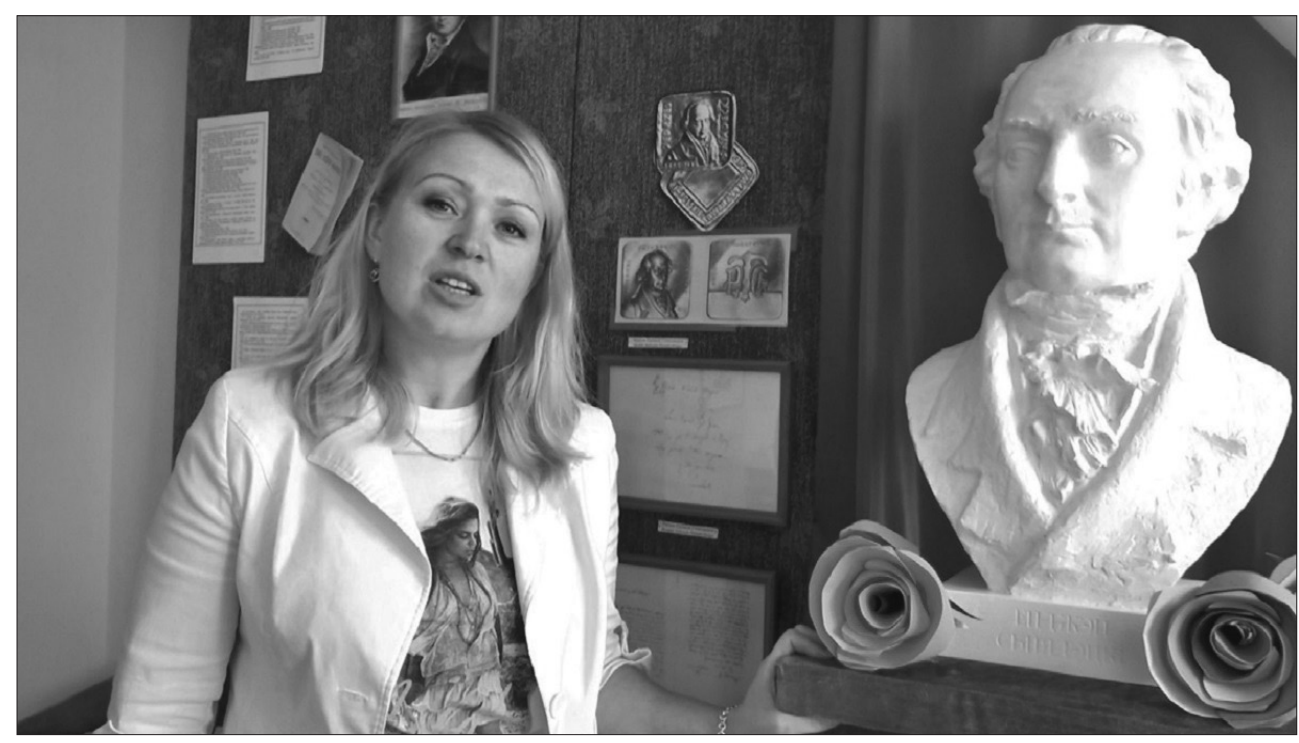

Il. 2. Tatiana Dawidowicz w Muzeum w Szkole Średniej w Kolczunach, Białoruś [w:] T. Dawidowicz, op. cit., s. 13

Po śmierci Jędrzeja Śniadeckiego majątkiem Bołtupie zarządzali syn Józef i wnuk Andrzej. Dworek przeszedł na własność córki Andrzeja - Zofii Osiecimskiej, która sprzedała go ostatnim właścicielom majątku rodzinie Oskierków. Zajmowała ona Bołtupie do 1939 roku. 


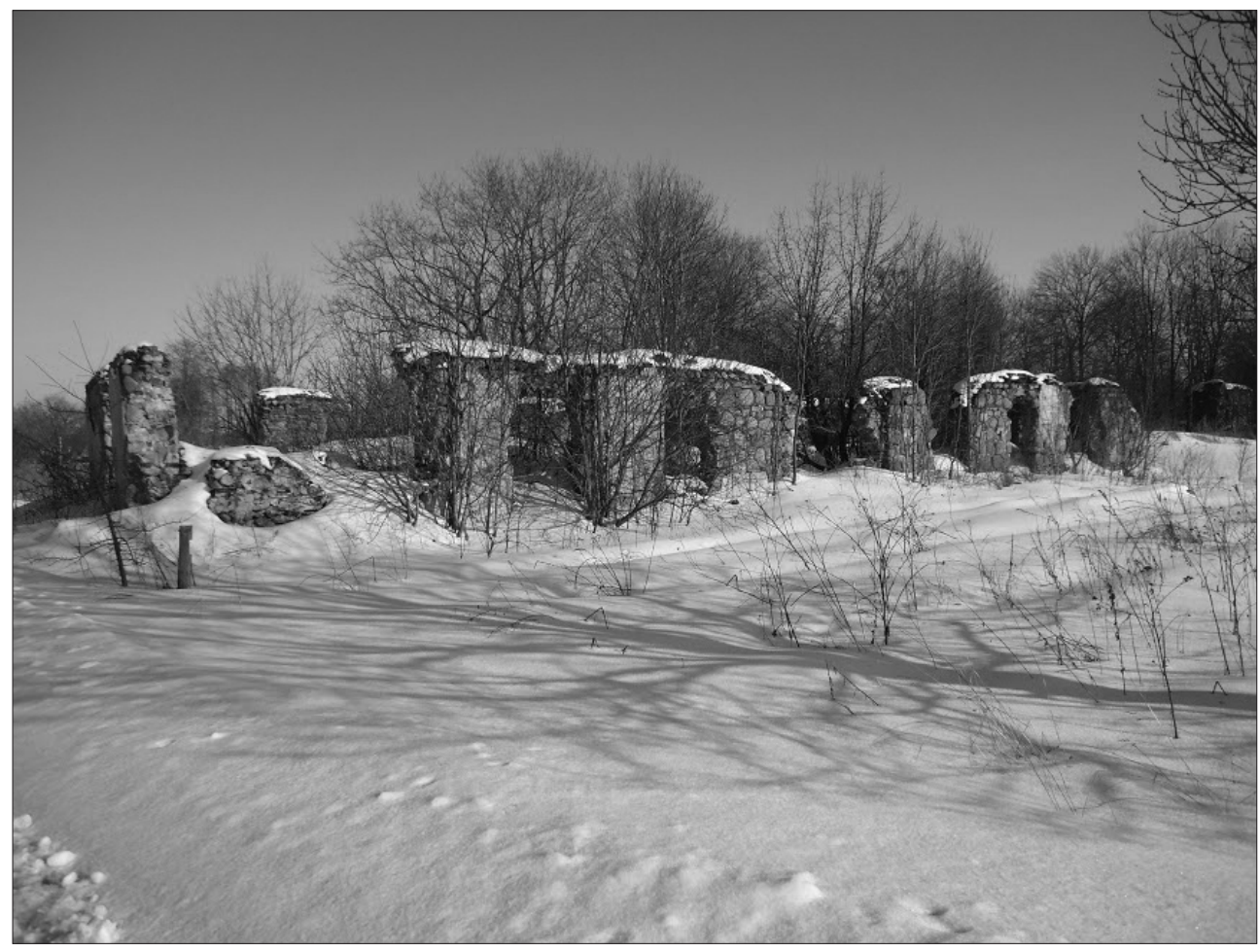

Il. 3. Widok współczesny pozostałości po budynku. Fot. T. Dawidowicz

Po wojnie zniszczony posłużył on jako źródło cegły na powstające inne zabudowania. Obecnie budynek już nie istnieje, pozostały tylko ruiny coraz bardziej zanikające ${ }^{13}$ (il. 3). Pozostały do dziś pamięć po uczonym i jego dorobek.

\section{Bibliografia}

Aftanazy R., Dzieje rezydencji na dawnych kresach Rzeczypospolitej, t. 4: Województwo wileńskie, wyd. 2, Wrocław 1993.

Baliński M., Dzieła Jędrzeja Śniadeckiego, t. 1, Warszawa 1840.

Baliński M., Życie Jędrzeja Śniadeckiego, Leszno, Gniezno 1840.

Barański A., Warsza L.Z., Miary na ziemiach polskich w dobie porozbiorowej, „Pomiary, Automatyka, Kontrola PAK” 2012, vol. 58, nr 12, s. 1137-1140.

Bieliński J., Uniwersytet Wileński (1579-1831), t. 1, Kraków 1899-1900.

Chrzęściewski L., Jędrzej Śniadecki: życie i dzieło, Prace Monograficzne Wyższej Szkoły Pedagogicznej w Krakowie, t. 21, Kraków 1978.

13 T. Dawidowicz, Pamięć o Jędrzeju Śniadeckim na Oszmiańszczyźnie, „Pałuki” 2018, nr 1, s. 13; Bottup [w:] R. Aftanazy, Dzieje rezydencji na dawnych kresach Rzeczypospolitej", t. 4: Województwo wileńskie, wyd. 2, Wrocław 1993, s. 47-50. 
Clifton G., Directory of British Scientific Instrument Makers 1550-1851, National Maritime Museum, London 1995.

Dawidowicz T., Pamięć o Jędrzeju Śniadeckim na Oszmiańszczyźnie, „Pałuki” 2018, nr 1, s. 13. Fenna D., Jednostki miar. Leksykon, red. B. Pierzchalska, przeł. J. Gronkowski, J. Kuśmierczyk, Warszawa 2004.

Gajek M., Szpada paradna po Jędrzeju Śniadeckim, karta katalogu naukowego Muzeum UJ nr in. 123939, 3035/IV.

Raileinè B., Andrius Sniadeckis, Vilnius 2005.

Taborska M., Mikroskop optyczny po prof. Jędrzeju Śniadeckim, karta katalogu naukowego Muzeum Uniwersytetu Jagiellońskiego nr MUJ 4136, 136/V.

Taborska M., Przymiar 24-calowy po Jędrzeju Śniadeckim, karta katalogu naukowego Muzeum Uniwersytetu Jagiellońskiego nr MUJ 4053, 53/V. 



\section{Ewa Wyka}

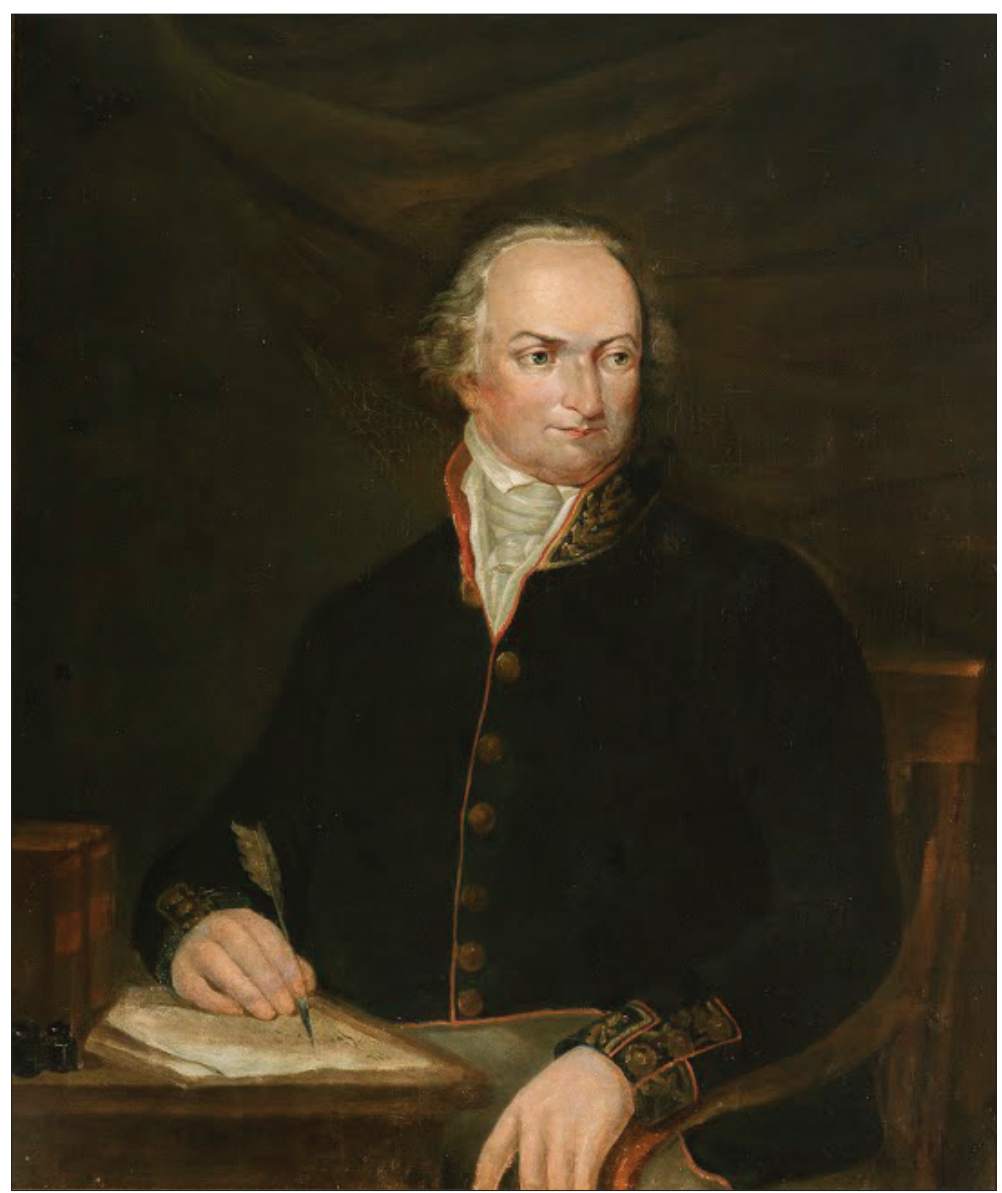

Il. I. Portret Jędrzeja Śniadeckiego, mal. Medard Rudnicki, 1888 r., Muzeum UJ, nr 2577, 504/I. Fot. J. Kozina

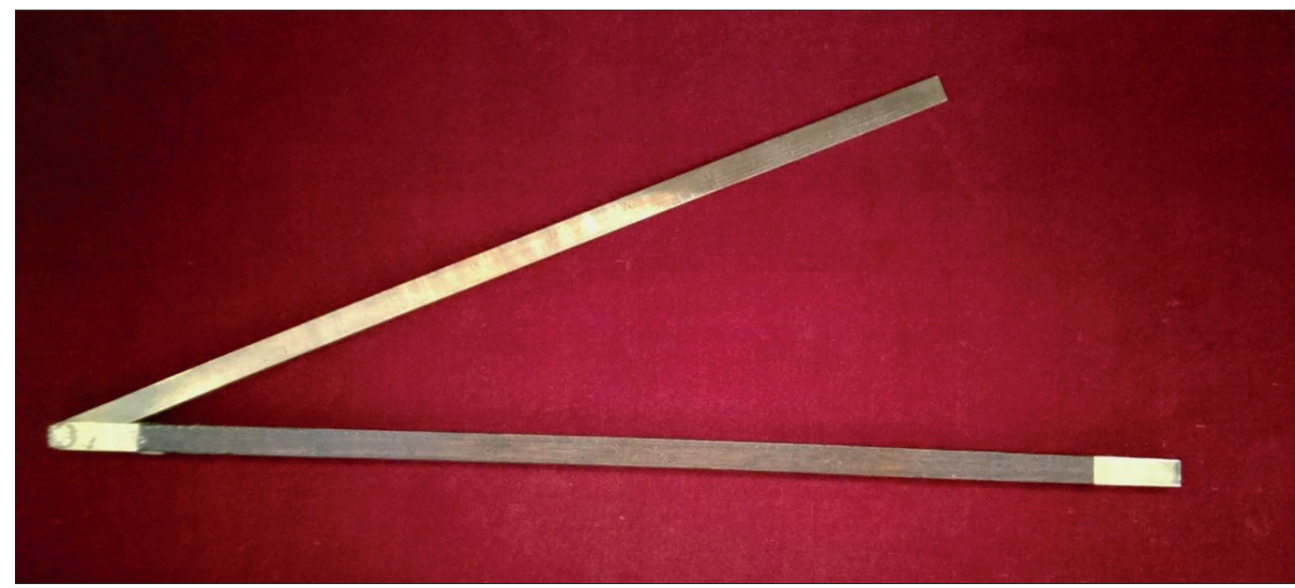

Il. II. Dwuczęściowy przymiar składany, 24-calowy, Prusy, 1834 r., Muzeum UJ, nr 4053, 53/V. Fot. G. Zygier 


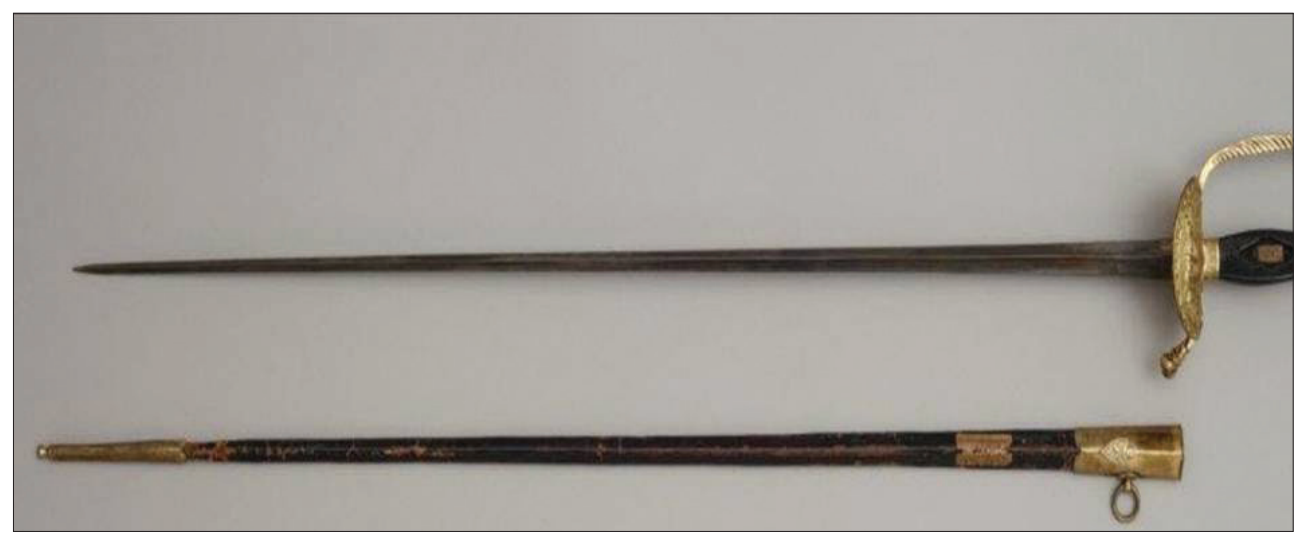

Il. III. Szpada paradna do stroju uniwersyteckiego, Francja (?), pocz. XIX w., Muzeum UJ, nr 123939, 3035/IV. Fot. G. Zygier

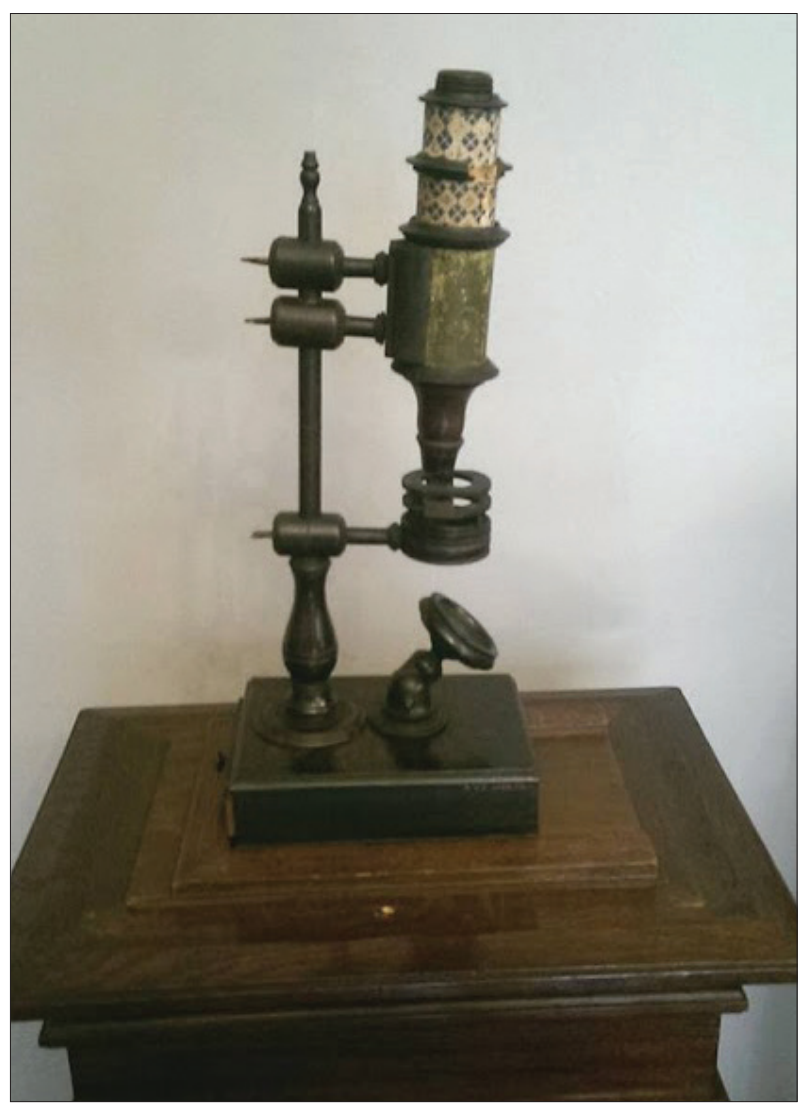

Il. IV. Mikroskop optyczny po Jędrzeju Śniadeckim, Muzeum UJ, nr 4136, 136/V, poł. XVIII w. Fot. J. Kozina 